\title{
A new simplified technique for artificial chordae implantation in mitral valve repair with its early results
}

\author{
Mohamed El Gabry, Fanar Mourad”, Lisa Loosen, Arjang Ruhparwar, Ender Demircioglu, Daniel Wendt, \\ Heinz Jakob, Sharaf-Eldin Shehada" \\ Department of Thoracic and Cardiovascular Surgery, West German Heart and Vascular Centre Essen, University Hospital Essen, Essen, Germany \\ Contributions: (I) Conception and design: SE Shehada, M El Gabry; (II) Administrative support: M El Gabry; (III) Provision of study materials or \\ patients: F Mourad, SE Shehada, M El Gabry; (IV) Collection and assembly of data: L Loosen, F Mourad; (V) Data analysis and interpretation: SE \\ Shehada, F Mourad; (VI) Manuscript writing: All authors; (VII) Final approval of manuscript: All authors. \\ "These authors contributed equally to this work and share senior authorship. \\ Correspondence to: Sharaf-Eldin Shehada, MD. Department of Thoracic and Cardiovascular Surgery, West German Heart and Vascular Centre Essen, \\ University Hospital Essen, Hufelandstraße 55, 45147 Essen, Germany. Email: sharaf.shehada@live.com.
}

Background: Many techniques in mitral valve repair (MVR) have been reported with successful longterm results. The aim of this study is to present our simplified technique in artificial chordae replacement for MVR, and reporting its short-term outcomes.

Methods: We present a prospective single-surgeon experience. A new simplified artificial chordae implantation technique has been used to repair mitral valves. Postoperative echocardiography at 0,6 , then every 12 months is used to control the results. Endpoints involved freedom from mitral regurgitation (MR), reoperation and major adverse cardiac and cerebrovascular events (MACCE).

Results: Between 01/2016 and 01/2018, 57 consecutive patients undergo MVR using this technique are evaluated. Mean age was $63.6 \pm 10.1$ years and $68.4 \%$ were male. Mitral valve pathology was mainly degenerative $(52,91.2 \%$ ) or healed endocarditis (5, 8.8\%). Besides chordae replacement (3.6 \pm 1.1 per patient), annuloplasty was used in all patients to correct annulus dilation and stabilize the repair. Mean cross-clamping time was $53 \pm 13.4$ minutes in isolated MVR and $69.4 \pm 31.1$ minutes in concomitant procedures. Postoperative outcomes reported two mortalities. Discharge echocardiography reported mild MR in 4 patients and the rest of patients had non-to trace regurgitation. Follow-up results within a mean of $19.3 \pm 8.5$ months reported no significant MR or need for reoperation and three more (non-valve related) mortalities.

Conclusions: Our simplified technique allows to reduce the number of used chordae and re-correction if needed, which consequently reduces cross-clamping and bypass time especially in endoscopic MVR. Good intraoperative and short-term results are reported. These results are still under investigation to prove longterm stability of the repair.

Keywords: Mitral valve repair (MVR); chordae tendineae; expanded polytetrafluoroethylene

Submitted Jun 23, 2019. Accepted for publication Nov 15, 2019.

doi: $10.21037 /$ jtd.2019.12.105

View this article at: http://dx.doi.org/10.21037/jtd.2019.12.105

\section{Introduction}

Mitral valve repair (MVR) is considered the procedure of choice for correcting mitral regurgitation (MR) in degenerative $M V$ disease (1), providing long-term results that are superior to those with valve replacement (2). The use of artificial chordae to replace elongated or ruptured chordae causing leaflet prolapse and MR has been the subject of extensive work to define feasibility, reproducibility and effectiveness of this procedure. Artificial chordae made of autologous or xenograft pericardium has been replaced by chordae manufactured of expanded polytetrafluoroethylene 


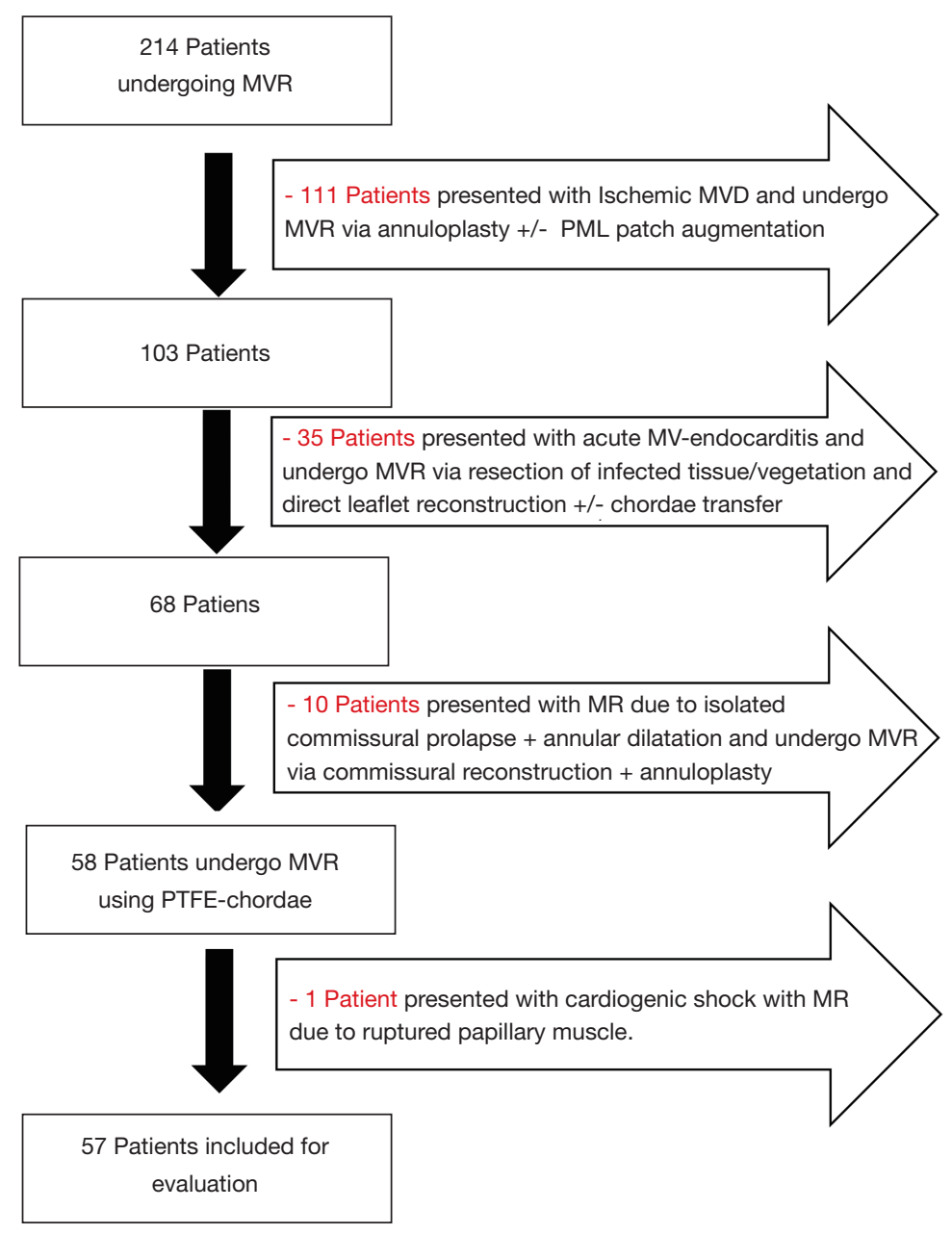

Figure 1 Study flowchart. MVR, mitral valve repair; PTFE, polytetrafluoroethylene.

(PTFE) (W.L. Gore \& Association, Inc., Flagstaff, USA), a material with the unique property of becoming covered by host fibrosa and endothelium. The use of artificial chordae made of PTFE has been validated clinically over the past two decades and has been an increasing component of the surgical armamentarium for MVR. A variety of reliable techniques are now available for management of chordae pathologies to repair mitral valve. Therefore, we aimed in this study is to present our simplified technique in using PTFE chordae to correct the prolapsed MV and reporting our short-term results of this technique.

\section{Methods}

\section{Study design}

This is a retrospective sampled observational study, whereas data of all patients referred to our institute with mitral valve disease was entered in a database. Patients' preoperative, operative and postoperative data were predefined, recorded in our institutional database. Publication of the validated data in anonymous manner obtained a review board approval according to the University-Hospital-EthicsCommittee (Ref\#20-9128-BO). Over a 2-year period between 01/2016 and 01/2018, 214 patients underwent MVR by a single surgeon were reported. Of these patients 57 patients with leaflet prolapse have got isolated PTFE chordae replacement using our simplified technique and annuloplasty with a flexible band. The rest of the patients became repair through other techniques "e.g., isolated annuloplasty repair, endocarditis limited resection repair (3), commissural reconstruction and/or patch augmentations" as reported in the flowchart (Figure 1). Echocardiographic 
evaluation of the MV took place preoperative, before discharge, 6 months after surgery and at 12-month interval thereafter. Follow-up was continued until completion of the study through January 2019 allowing a 12-month minimum and a mean of $19.3 \pm 8.5$ months. However, 2 patients were clinically stable and refuse repeated echocardiographic follow-up.

\section{Study endpoints and definitions}

The study endpoints included mainly outcomes of the repaired mitral valves, i.e., freedom from regurgitation and reoperation, as well as the incidence of major adverse cardiac and cerebrovascular events (MACCE). Echocardiographic evaluation consisted of qualitative evaluation of the mitral valve function and quantitative measurement of the left ventricular function. Mitral valve regurgitation was graded as non-to-trace, mild, moderate or severe as reported In the guidelines (4) and the left ventricular function was measured in terms of the left ventricular ejection fraction (LVEF).

Non-elective surgery was urgent or emergent, as defined in the Society of Thoracic Surgeons database. Low cardiac output syndrome was defined as perioperative need for intra-aortic balloon pump (IABP) or extra-corporal membrane oxygenator (ECMO) support. Postoperative myocardial infarction (MI) was defined in reference to the Third-Universal-Definition of MI (5). Respiratory insufficiency was defined by the need of re-intubation or prolonged mechanical ventilation requiring percutaneous tracheostomy and gradual weaning. Cerebrovascular event was defined with incidence of stroke. MACCE has been defined as incidence of overall mortality, MI, stroke or need for re-intervention (either percutaneous or operative).

\section{Surgical technique}

A standard full sternotomy with central "ascending aortic and bicaval" cannulation for cardiopulmonary bypass (CPB) for concomitant procedures or a right lateral minithoracotomy with peripheral "femoral vessels and right jugular vein" cannulation for isolated mitral +/- tricuspid valve(s) surgery. After initiation of CPB, the distal ascending aorta was cross-clamped and myocardial protection was obtained with moderate systemic hypothermia $\left(30^{\circ} \mathrm{C}\right)$ and antegrade cold crystalloid cardioplegia (Custodiol,
Franz Köhler Chemie, Bensheim, Germany). The MV was approached through a left atriotomy in case of isolated $M V$-surgery or via a trans-septal approach if concomitant tricuspid valve surgery was planned. After exposure of the MV, a detailed mitral valve inspection and segmental analysis are carefully done. As a first step of Chordae replacement, one or more 4/0 PTFE chordae (W.L. Gore \& Association, Inc., Flagstaff, USA) are passed through the fibrous head of the corresponding papillary muscle as a figure of eight without any pledged (Figure 2A). The two arms of each neo-chordae will then pass through the free margin of the prolapsing leaflet segment in a distance of $10 \mathrm{~mm}$, again as a figure of eight but in a lock maneuver (Figure 2B). To adjust the length of the neo-chordae, the free margin of the prolapsing segment will be approximated by a forceps to the opposite side of the annular plan (in case of anterior leaflet prolapse), or 5 to $10 \mathrm{~mm}$ underneath the annular plan (in case of posterior leaflet prolapse) and gently the lock suture will be closed to fix the length (Figure 2C). Water probe should be done to test the repaired segment, in case of none satisfactory result, the lock suture can be easily reopened to correct the proper length of the neochordae. When the water probe is satisfactory, a back stich will be done in the middle of the $10 \mathrm{~mm}$ distance to the ventricular side, to reinforce this distance, followed by tying the knots underneath the leaflet (Figure 2D). This maneuverer reinforces the corrected segment and provides a smooth surface of coaptation. Finally, an annuloplasty device is implanted with interrupted sutures. The size of the device is selected according to the inter-trigonal distance or the surface area of the anterior leaflet as known. A transesophageal echocardiography (TOE) was applied in all cases before and after CPB to control function of the repaired valve. Our simplified technique is presented in details in Video 1 (supplementary data), with an illustrating step by step diagram (Figure 3).

\section{Statistical analysis}

Statistical analyses were performed with the SPSS software (version 22.0. Armonk, NY: IBM Crop.). Continuous data were summarized as mean \pm standard deviation (SD) for normally distributed data, or median with interquartile range [IQR] $\left(25^{\text {th }}-75^{\text {th }}\right.$ percentiles $)$ for skewed data. Categorical data were summarized as frequencies and percentages. Kaplan-Meier curves was generated to estimate follow-up overall survival as well as freedom from MACCE. 

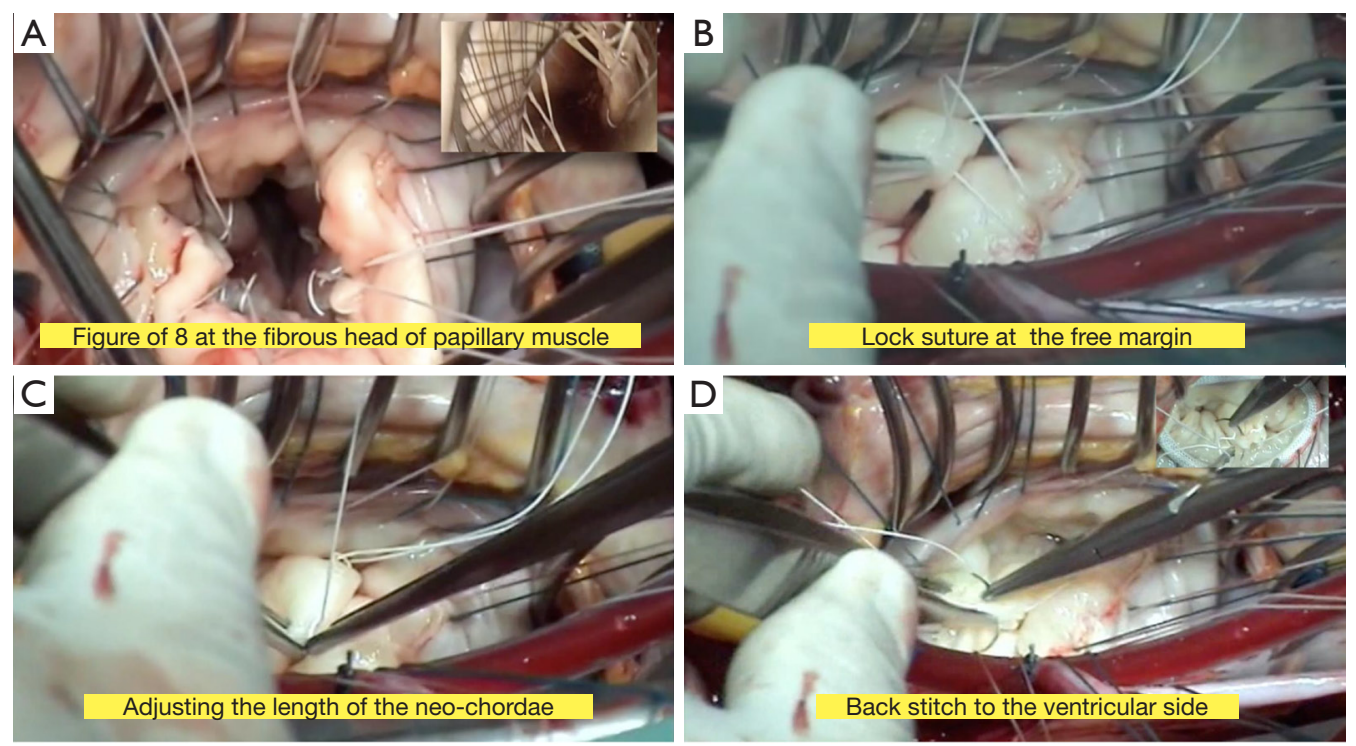

Figure 2 Intraoperative images showing PTFE-chordae implantation technique. (A) A figure of eight insertion of the PTFE-chordae at the fibrous band. (B) Insertion of both arms into the free leaflet margin and creating a lock suture. (C) Adjusting the length of the PTFE chordae using 2 forceps. (D) Back stitch to knot the chordae at the ventricular side. PTFE, polytetrafluoroethylene.

\section{Results}

\section{Baseline characteristics}

Mean patients' age is $63.6 \pm 10.1$ years and most of the patients are males $(39,68.4 \%)$. Majority of patients (52/91.2\%) presented with degenerative mitral valve disease. The other five $(8.8 \%)$ patients presented with moderate regurgitation $(2+)$ due to limited chordae rupture caused by healed mitral valve endocarditis (history of infection and local operative finding). Reported regurgitation was due to prolapse of the anterior $(12,21.1 \%)$, posterior $(40,70.2 \%)$ or both $(5,8.8 \%)$ leaflets (Carpentier classification type II). Seven patients had impaired left ventricular functions, and two patients had previous cardiac surgery. Concomitant atrial fibrillation was reported in $15(26.3 \%)$ patients, aortic and tricuspid valve pathologies were present in 11 (19.3\%) patients and $6(10.5 \%)$ patients had concomitant coronary artery disease. Patient baseline and preoperative data are summarized in Tables 1,2.

\section{Operative outcomes}

Table 3 summarizes intraoperative results, all the 57 patients underwent successful MVR. Technique of MVR was exclusively based on PTFE-chordae replacement. Annuloplasty using flexible band was performed in all patients to correct additional annular dilatation and support the repair. Minimal invasive surgery through lateral mini-thoracotomy was done in 11 (19.3\%) patients. Twenty $(35.1 \%)$ patients undergo one or more concomitant procedures; coronary artery bypass grafting in $5(8.8 \%)$ patients, aortic valve replacement in $3(5.3 \%)$ patients, tricuspid valve repair in $8(14 \%)$ patients and other procedures in $10(17.5 \%)$ patients ( closure of a patent foramen oval, left atrial appendage or extraction of an infected pacemaker leads). Mean cross-clamp time was $69.4 \pm 31.1$ minutes in concomitant procedure and $53 \pm 13.4$ minutes in isolated MVR. Intraoperative TOE was performed before and after CPB to control the results. No second run on $\mathrm{CPB}$ or conversion to valve replacement was necessary in any of the patients.

\section{Early and follow-up outcomes}

Postoperative outcomes are summarized in Table 4. Thirtyday mortality was reported in $2(3.5 \%)$ patients, both of them presented with concomitant heart pathologies, the first one has had an additional coronary artery disease and tricuspid valve regurgitation with severely impaired left ventricular function ( $\mathrm{LVEF}=15 \%$ ), who develop multiorgan failure. The second patient presented with concomitant tricuspid valve regurgitation and severe pulmonary hypertension (systolic 

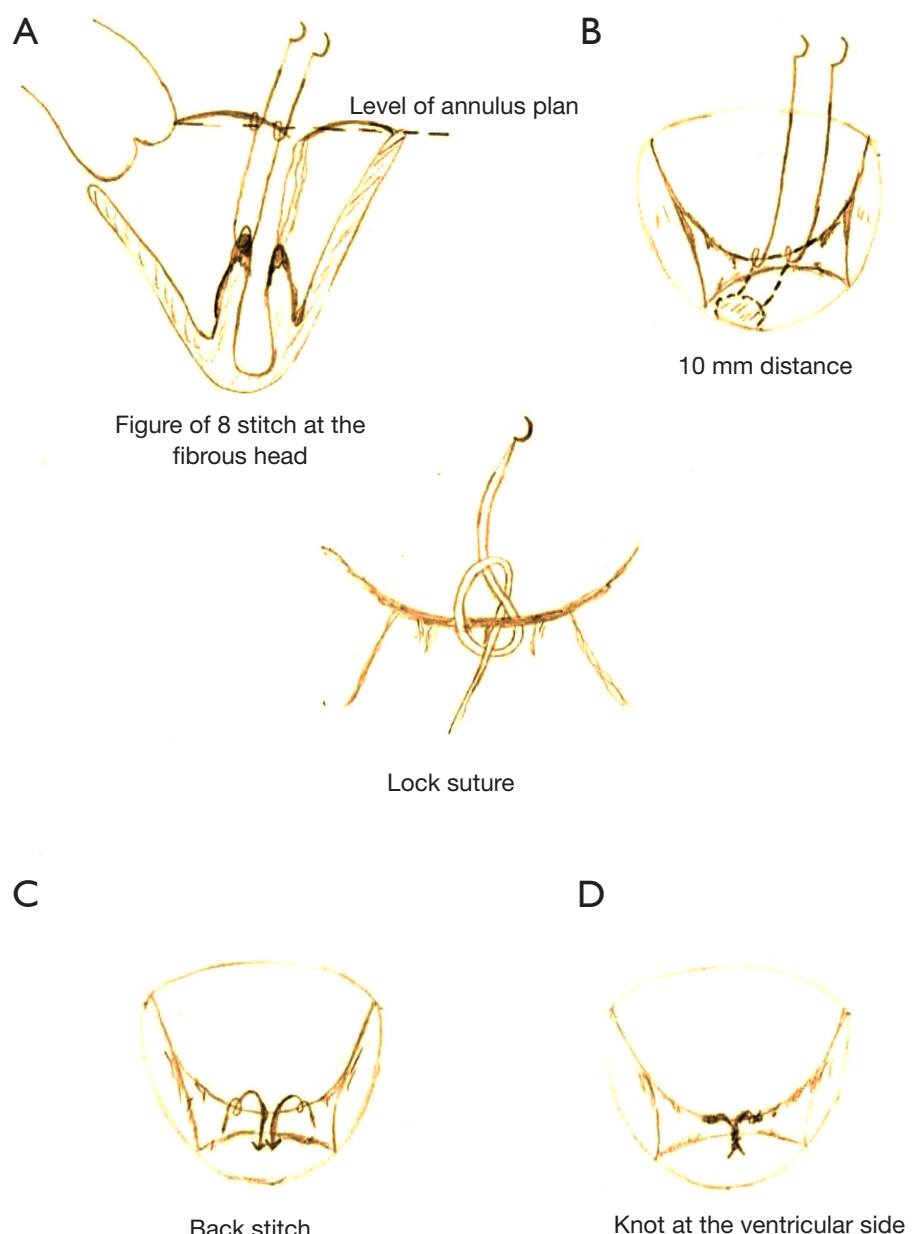

Figure 3 Illustrating diagram showing the concept our simplified technique.

pressure of $85 \mathrm{mmHg}$ ) and developed multiorgan failure on top of pneumogenic sepsis. Two (3.5\%) patients developed postoperative acute kidney injury requiring hemodialysis and one patient developed stroke. Discharge echocardiography reported mild MR in $4(7 \%)$ patients and the rest of the patients have had non-to trace MR.

Follow-up results within a mean of $19.3 \pm 8.5$ months reported no significant MR or need for reoperation [non-to trace MR in $45(90 \%)$ patients, mild MR in 4 (8\%) patients and moderate MR in 1 (2\%) patient (Table 5)]. One patient developed stroke, another patient had MI, two patients needed coronary intervention and three more mortalities were reported. One of them due to massive stroke and brain herniation with poor prognosis, the second one due to sepsis caused by wound infection after pacemaker implantation and cause of death in the last one is unknown.

\section{Discussion}

After several years of unsuccessful experimentation with chordal substitutes (6), the decade of the 1980s saw an introduction of the PTFE sutures (W.L. Gore \& Association, Inc., Flagstaff, USA) into surgical practice by Reveulta in Spain, Frater in New York, and David in Toronto (7-10). With time, chordae replacement with PTFE suture has proven to be a simple, versatile, and durable technique (11-13). Those investigators reported various advantages of the use of PTFE chordae including: (I) normal leaflet motion is not disturbed as there is no need for native chordal transposition, especially in myxomatous degeneration where chordae weakness is the main cause of prolapse; (II) the number of PTFE chordae, which can be used is unlimited, especially when both leaflets have 
Table 1 Baseline patients' characteristics

\begin{tabular}{|c|c|}
\hline Variable & All patients $(\mathrm{N}=57)$ \\
\hline \multicolumn{2}{|l|}{ Demographics } \\
\hline Age, years & $63.6 \pm 10.1$ \\
\hline Gender, male & $39(68.4)$ \\
\hline $\mathrm{BMI}, \mathrm{kg} / \mathrm{m}^{2}$ & $26 \pm 3.3$ \\
\hline \multicolumn{2}{|l|}{ Risk factors \& comorbidities } \\
\hline Peripheral vascular disease & $2(3.5)$ \\
\hline Systemic hypertension & $43(75.4)$ \\
\hline COPD & $10(17.5)$ \\
\hline Renal failure & $17(29.8)$ \\
\hline Diabetes mellitus & 7 (12.3) \\
\hline Pulmonary hypertension & $31(54.4)$ \\
\hline Hyperlipidemia & $32(56.1)$ \\
\hline Previous myocardial infarction & $4(7.0)$ \\
\hline Previous stroke & $6(10.5)$ \\
\hline Previous cardiac surgery & $2(3.5)$ \\
\hline \multicolumn{2}{|l|}{ NYHA-classification } \\
\hline NYHA I-II & $41(71.9)$ \\
\hline NYHA III-IV & $17(29.8)$ \\
\hline \multicolumn{2}{|l|}{ Left ventricular ejection function } \\
\hline Normal ( $\geq 50 \%)$ & $50(87.7)$ \\
\hline Impaired (<50\%) & 7 (12.3) \\
\hline \multicolumn{2}{|l|}{ Risk-SCORES } \\
\hline STS-Prom for mortality & $1.4(0.9-1.7)$ \\
\hline STS-Prom for morbidity \& mortality & $13.4(11-16.2)$ \\
\hline EuroSCORE log I & $5(2.4-8.7)$ \\
\hline EuroSCORE II & $1.9(1.3-2.1)$ \\
\hline
\end{tabular}

Data presented as mean \pm SD or number (\%) or median and (IQR). BMI, body mass index; COPD, chronic obstructive pulmonary disease; NYHA-classification, New York Heart Association Classification; STS, Society of thoracic surgery; EuroSCORE, European system for cardiac operative risk evaluation.

to be addressed. Where, in older techniques bileaflet prolapse is more difficult to be repaired and may be associated with higher rate of repair failure leading to valve replacement (12), the use of artificial chordae made this kind of repair more feasible.
Table 2 Preoperative mitral and other cardiac pathologies

\begin{tabular}{lc}
\hline Variable & All patients (N=57) \\
\hline Grade of mitral regurgitation & $5(8.8)$ \\
Grade $2+^{*}$ & $52(91.2)$ \\
Grade 3-4+ & \\
Pathogenesis of mitral regurgitation & $5(8.8)$ \\
Healed endocarditis & $52(91.2)$ \\
Degenerative & $5 / 52$ \\
$\quad$ Barlow disease & \\
Mechanism of MR "Carpentier classification type II" & $40(70.2)$ \\
Posterior mitral leaflet prolapse & $12(21.1)$ \\
Anterior mitral leaflet prolapse & $5(8.8)$ \\
Both leaflet prolapse (Barlow) & \\
Other cardiac pathologies & $3(5.3)$ \\
Aortic valve disease & $8(14)$ \\
Tricuspid valve regurgitation & $6(10.5)$ \\
Coronary heart disease & $15(26.3)$ \\
Atrial fibrillation &
\end{tabular}

Data are presented as number (\%). *, MV-regurgitation due to status post healed endocarditis.

Our simplified technique of chordae replacement (14) can be used in all cases of leaflet prolapse regardless of the site. The main difference in this technique compared with other reports is the reduction of the number of chordae needed for the repair by using both arms of the PTFE chordae in a wide $(10 \mathrm{~mm})$ area of the prolapsed segment, which in turn reduces the rate of error and repair time. The back stitch to the ventricular side in the middle of the $10 \mathrm{~mm}$ area provides a reinforcement of the repaired segment. Additionally, the lock suture allows an easier and faster readjustment of the length of the PTFE-chordae after the water probe if necessary. In the current study an average of 3.6 chordae per patient have been implanted, within a mean cross clamp time of 53 minutes in isolated MV-repair and 69 minutes in commitment procedures. These findings are comparable to reports from other investigators, where a mean of 4 to 8 PTFE-chordae per patient were required for a repair within a mean cross clamp time of $\sim 84-101$ minutes based on the type of procedure $(15,16)$.

In case of anterior leaflet prolapse we are using the 
Table 3 Operative outcomes

\begin{tabular}{|c|c|}
\hline Variable & All patients $(\mathrm{N}=57)$ \\
\hline \multicolumn{2}{|l|}{ Indication for surgery } \\
\hline Elective & $52(91.2)$ \\
\hline Non-elective & $5(8.8)$ \\
\hline \multicolumn{2}{|l|}{ Operative details } \\
\hline Minimal invasive procedure & $11(19.3)$ \\
\hline Cross-clamp time, $\min$ & $69.4 \pm 31.1$ \\
\hline Cardiopulmonary bypass time, min & $101.8 \pm 44.4$ \\
\hline Cross-clamp time for isolated MVR, $\min$ & $53 \pm 13.4$ \\
\hline $\begin{array}{l}\text { Cardiopulmonary bypass time for isolated } \\
\text { MVR, min }\end{array}$ & $78.4 \pm 17.7$ \\
\hline \multicolumn{2}{|l|}{ Technique of mitral valve repair } \\
\hline Artificial chordae replacement & $57[100]$ \\
\hline Number of chordae used per patient & $3.6 \pm 1.1$ \\
\hline Annuloplasty & $57[100]$ \\
\hline Concomitant procedure & $20(35.1)$ \\
\hline Aortic valve replacement & $3(5.3)$ \\
\hline Tricuspid valve repair & $8(14.0)$ \\
\hline Coronary artery bypass grafting & $4(7.0)$ \\
\hline Others & $10(17.5)$ \\
\hline
\end{tabular}

Data presented as mean \pm SD or number (\%). MVR, mitral valve repair.

annular level of the opposite side (posterior mitral annulus) as a landmark to adjust the length of the PTFE-chordae. On the other hand, in case of posterior leaflet prolapse, we always performing an overcorrection $(5-10 \mathrm{~mm}$ underneath the annular plan) to avoid the incidence of systolic anterior motion (SAM) phenomenon, which is not rare in degenerative $M V$ diseases with excess tissue. Additionally, making knots underneath the leaflet provides smooth surface of coaptation, avoiding risk of residual regurgitation and/or hemolysis.

Loss of the three-dimensional annular appearance due to annulus dilatation is an important additional pathology in case of mitral valve regurgitation, hence restoration of the normal annular dimensions is mandatory to achieve complete successful repair, and to avoid early repair failure. Since Lillehei et al. introduced the mitral annuloplasty concept in 1957 (17), different techniques has been developed to preserve annular function including suture or
Table 4 Postoperative and follow-up outcomes

\begin{tabular}{lc}
\hline Variable & All patients (N=57) \\
\hline Early postoperative outcomes & $57[100]$ \\
30-day mortality & $2(3.5)$ \\
Stroke & $1(1.7)$ \\
Myocardial infarction & 0 \\
Low cardiac output syndrome & $2(3.5)$ \\
Respiratory Insufficient & \\
Re-intubation & $4(7.0)$ \\
Tracheotomy & $4(7.0)$ \\
Dialysis & $2(3.5)$ \\
Revision for bleeding & $5(8.8)$ \\
Wound infection & $2(3.5)$ \\
Intensive care unit stay, days & $2.6 \pm 2.2$ \\
Hospital stay, days & $16.3 \pm 10.7$ \\
Follow-up outcomes & $55[100]$ \\
Mean follow-up, months & $19.3 \pm 8.5$ \\
Follow-up mortality & $3(5.5)$ \\
Myocardial infarction & $1(1.8)$ \\
Percutaneous coronary intervention & $2(3.6)$ \\
Stroke & $1(1.8)$ \\
\hline Re-operation & 0 \\
\hline
\end{tabular}

Data presented as mean \pm SD or number (\%).

ring annuloplasty, however ring annuloplasty has proven to be superior than the suture one (18). In our experience, annuloplasty is mandatory in order correct the annular dilation and to support the repair.

Different outcomes as well as different techniques for MVR using artificial chordae have been reported $(12,19,20)$. The variety of the implantation techniques, surgeons' experience, heterogenicity of patients population and mitral valve pathology impede an accurate evaluation and comparison of the use of artificial chordae, considering short- and long-term outcomes of the repair.

In the current study none of the patients needed intraoperatively a second run on bypass nor a reoperation during follow-up. Echocardiographic follow-up confirms the stability of the repair using this simplified technique over a mean time of 19.3 months (range, 12-36 months), only one patient developed moderate MR (2+), without 
Table 5 Echocardiography data

\begin{tabular}{|c|c|c|c|}
\hline Variable & Preoperative $(\mathrm{N}=57)$ & Before discharge $(\mathrm{N}=55)$ & At last follow-up $(\mathrm{N}=50)$ \\
\hline None-to-trace & 0 & $51(92.7)$ & $45(90.0)$ \\
\hline Mild (grade 1+) & 0 & $4(7.3)$ & $4(8.0)$ \\
\hline Moderate (grade 2+) & $5(8.8)$ & 0 & $1(2.0)$ \\
\hline \multicolumn{4}{|l|}{ Left ventricular ejection fraction (LVEF) } \\
\hline LVEF >50\% & $50(87.7)$ & $50(90.9)$ & $45(90.0)$ \\
\hline LVEF $=30-50 \%$ & $5(8.8)$ & $5(9.1)$ & $5(10.0)$ \\
\hline LVEF $<30 \%$ & $2(3.5)$ & 0 & 0 \\
\hline
\end{tabular}

Data presented as number and (\%) or median and (IQR).

any clinical symptoms. In the majority of the patients, non-to trace MR with significant improvement of clinical symptoms could be reported. In spite of these promising outcomes, long-term follow-up is still under investigation to prove the durability of this repair technique.

\section{Study limitations}

This study is a single center study with a relatively small number of patients, it presents however our primary results of this simplified technique. No patients' selection has been made and the study evaluated all patients undergoing MVR using PTFE-chordae, this for sure impacted the outcomes especially overall mortality. The study is retrospective one with short time period, thus mid- and long-term results are still under investigation.

\section{Conclusions}

Our modified implantation technique simplifies MVR, it allows to reduce the number of the used chordae and re-correction if needed, which consequently reduces procedural time, especially in endoscopic MVR. It also reduces the risk of SAM phenomenon through PML overcorrection, that in turn minimize possibilities of failure. Re-stitching and tying the knots at the ventricular side of the leaflet provides a reinforcement of the corrected segment and allows a smooth surface of coaptation to avoid residual MR or hemolysis. Good intraoperative and shortterm results are reported till now.

\section{Acknowledgments}

The study presented at the $68^{\text {th }}$ international congress of the European Society for Cardiovascular and Endovascular Surgery, on 22-24 May 2019 in Groningen, The Netherlands. The authors are sincerely grateful to Andreas Sander (Institute of Quality Controlling, West German Heart and Vascular Centre Essen) for his enormous efforts and support in data acquisition to finish this work.

Funding: None.

\section{Footnote}

Conflicts of Interest: DW serves as the unpaid editorial board member of Fournal of Thoracic Disease from Feb 2018 to Apr 2020. The other authors have no conflicts of interest to declare.

Ethical Statement: The authors are accountable for all aspects of the work in ensuring that questions related to the accuracy or integrity of any part of the work are appropriately investigated and resolved. The study obtained IRB-approval (20-9128-BO) according to the Declaration of Helsinki.

Open Access Statement: This is an Open Access article distributed in accordance with the Creative Commons Attribution-NonCommercial-NoDerivs 4.0 International License (CC BY-NC-ND 4.0), which permits the noncommercial replication and distribution of the article with 
the strict proviso that no changes or edits are made and the original work is properly cited (including links to both the formal publication through the relevant DOI and the license). See: https://creativecommons.org/licenses/by-nc-nd/4.0/.

\section{References}

1. Falk V, Baumgartner H, Bax JJ, et al. 2017 ESC/EACTS Guidelines for the management of valvular heart disease. Eur J Cardiothorac Surg 2017;52:616-64.

2. Shang X, Lu R, Liu M, et al. Mitral valve repair versus replacement in elderly patients: a systematic review and meta-analysis. J Thorac Dis 2017;9:3045-51.

3. El Gabry M, Haidari Z, Mourad F, et al. Outcomes of mitral valve repair in acute native mitral valve infective endocarditis. Interact Cardiovasc Thorac Surg 2019;29:823-9.

4. American College of Cardiology; American Heart Association Task Force on Practice Guidelines (Writing Committee to revise the 1998 guidelines for the management of patients with valvular heart disease); Society of Cardiovascular Anesthesiologists, et al. ACC/ AHA 2006 guidelines for the management of patients with valvular heart disease: a report of the American College of Cardiology/American Heart Association Task Force on Practice Guidelines (writing Committee to Revise the 1998 guidelines for the management of patients with valvular heart disease) developed in collaboration with the Society of Cardiovascular Anesthesiologists endorsed by the Society for Cardiovascular Angiography and Interventions and the Society of Thoracic Surgeons. J Am Coll Cardiol 2006;48:e1-148.

5. Thygesen K, Alpert JS, Jaffe AS, et al. Third universal definition of myocardial infarction. J Am Coll Cardiol 2012;60:1581-98.

6. Rittenhouse EA, Davis CC, Wood SJ, et al. Replacement of ruptured chordae tendineae of the mitral valve with autologous pericardial chordae. J Thorac Cardiovasc Surg 1978;75:870-6.

7. Revuelta JM, Garcia-Rinaldi R, Gaite L, et al. Generation of chordae tendineae with polytetrafluoroethylene stents. Results of mitral valve chordal replacement in sheep. J Thorac Cardiovasc Surg 1989;97:98-103.

8. Frater RW, Vetter HO, Zussa C, et al. Chordal replacement in mitral valve repair. Circulation 1990;82:IV125-30.

9. David TE, Bos J, Rakowski H. Mitral valve repair by replacement of chordae tendineae with polytetrafluoroethylene sutures. J Thorac Cardiovasc Surg 1991;101:495-501.
10. David TE. Replacement of chordae tendineae with expanded polytetrafluoroethylene sutures. J Card Surg 1989;4:286-90.

11. David TE, Armstrong S, Sun Z. Replacement of chordae tendineae with Gore-Tex sutures: a ten-year experience. J Heart Valve Dis 1996;5:352-5.

12. Lawrie GM, Earle EA, Earle NR. Feasibility and intermediate term outcome of repair of prolapsing anterior mitral leaflets with artificial chordal replacement in 152 patients. Ann Thorac Surg 2006;81:849-56; discussion 856.

13. Zussa C, Polesel E, Rocco F, et al. Surgical technique for artificial mitral chordae implantation. J Card Surg 1991;6:432-8.

14. El Gabry M, Jakob H, Lubarski J, et al. Minimally invasive video-assisted mitral valve repair using PTFE-chordae: a simplified technique. August 2018. doi:10.25373/ ctsnet.6990317.

15. Bogachev-Prokophiev AV, Afanasyev AV, Zheleznev SI, et al. Mid-term results of mitral valve repair using flexible bands versus complete rings in patients with degenerative mitral valve disease: a prospective, randomized study. J Cardiothorac Surg 2017;12:113.

16. Falk V, Seeburger J, Czesla M, et al. How does the use of polytetrafluoroethylene neochordae for posterior mitral valve prolapse (loop technique) compare with leaflet resection? A prospective randomized trial. J Thorac Cardiovasc Surg 2008;136:1205; discussion 1205-6.

17. Lillehei CW, Gott VL, Dewall RA, et al. Surgical correction of pure mitral insufficiency by annuloplasty under direct vision. J Lancet 1957;77:446-9.

18. Fedak PW, McCarthy PM, Bonow RO. Evolving concepts and technologies in mitral valve repair. Circulation 2008;117:963-74.

19. Chikwe J, Adams DH. State of the art: degenerative mitral valve disease. Heart Lung Circ 2009;18:319-29.

20. Salvador L, Mirone S, Bianchini R, et al. A 20-year experience with mitral valve repair with artificial chordae in 608 patients. J Thorac Cardiovasc Surg 2008;135:1280-7.

Cite this article as: El Gabry M, Mourad F, Loosen L, Ruhparwar A, Demircioglu E, Wendt D, Jakob H, Shehada SE. A new simplified technique for artificial chordae implantation in mitral valve repair with its early results. J Thorac Dis 2020;12(3):724-732. doi: 10.21037/jtd.2019.12.105 